\title{
Micromechanical Parameters from Macromechanical Measurements on Glass Reinforced Polypropylene
}

J. L. Thomason, European Owens Corning Fiberglas, s.a., Automotive Solutions Centre, Route de Charneux, B-4651 Battice, Belgium

Email james.thomason@strath.ac.uk

Keywords: Glass fibre, thermoplastic, interface, interfacial shear strength, fibre strength, orientation, injection moulding

\begin{abstract}
In recent years many elegant techniques have been developed for the quantification of composite micromechanical parameters. Unfortunately most of these techniques have found little enthusiastic support in the industrial product development environment. We have developed an improved method for obtaining the micromechanical parameters, interfacial shear strength, fibre orientation factor, and fibre stress at composite failure using input data from macromechanical tests. In this paper we explore this method through its application to injection moulded glass-fibre-reinforced thermoplastic composites. We have measured the mechanical properties and residual fibre length distributions of glass fibre reinforced polypropylene containing different levels of glass fibre. The level of fibre-matrix interaction in these composites was varied by the addition of maleic anhydride modified polypropylene "coupling agent". This data was used as input for the model. The trends observed for the resultant micromechanical parameters obtained by this method were in good agreement with values obtained by other methods. Given the wealth of microstructural information obtained from this macroscopic analysis and the low level of resources employed to obtain the data we believe that this method deserves further investigation as a screening tool in composite system development programmes.
\end{abstract}




\section{INTRODUCTION}

There has been a rapid growth in the development and application of fibre-reinforced thermoplastic polymer composites in recent years. Parallel to this growth has been the increasing recognition of the need to better understand and quantify the micromechanical parameters which control the strucure-property relationships in such composites. The properties of thermoplastic composites result from a combination of the fibre and matrix properties and the ability to transfer stresses across the fibre-matrix interface. Variables such as the fibre content, aspect ratio, strength, orientation and the interfacial strength are of prime importance to the final balance of properties exhibited by injection moulded thermoplastic composites (1-17). Fibre strength may be reduced significantly after fibre formation by damage caused during both the fibre and composite production processes $(16,17)$. Although there has not been any direct measurement of the residual strength of fibres in a moulded composite part, there is a growing body of indirect evidence that the strength of glass fibres may be significantly reduced by the time that they actually become the load bearing component of a composite $(3,7,16-19)$. The ability to transfer stress across the fibre-matrix interface is often reduced to a discussion of 'adhesion' which is a simple term to describe a combination of complex phenomena on which there is still significant debate as to what it means and how to measure it. Certainly, one of the generally accepted manifestations of 'adhesion' is in the mechanically measured value of interfacial shear strength (IFSS). However, many methods for determining IFSS exist and there is no overall consensus as to which method is best (20). This situation is further complicated by the fact that sample preparation for many of these techniques is not optimised for use with thermoplastic matrices.

Despite the elegance of the many techniques that have been developed for the quantification of composite micromechanical parameters, these techniques have found little enthusiastic support in the industrial product development environment. It should be clear that, the more dissimilar the experimental sample must be from the final composite part the greater must be the extrapolation and consequent uncertainty between the measured result and real composite performance. Furthermore, the higher the number of measurements that must be made for 'reliable' statistics, the longer and more labour intensive the measurement. Finally, the more complex and disputed the underlying theories supporting the analysis then, together with the foregoing, the less likely the technique is liable to gain acceptance in an industrial environment. There continues to be discussion and disagreement about many of these complex areas - which is healthy and acceptable in an academic environment - but gains little support in an industrial environment where time scales and resources are ever diminishing. It is unfortunate that many of these techniques are indeed viewed as time consuming, complex, inefficient, labour intensive, and in many cases unproven or inapplicable in 'real' systems. Consequently their application in most industrial product development programmes is rare. This leads to a classical situation where, because these methods have little support in an industrial environment, they rarely get the time and development to show their usefulness in that environment. This occurs despite the fact that even the most mundane industrial problems often require solutions that can only be obtained through a deep understanding of structure-performance relationships and microstructural analysis of composite materials. Many traditional product development strategies are reaching a level on the 'S-curve' of rapidly diminishing returns and there is a real need for a user-friendly micromechanics to aid composites to move to the next level of development. In addition to access to such knowledge, composite product developers also need tools that can fit their toolbox and do not need a new and expensive facility to house them. 
Most laboratories involved in the development of thermoplastic composites will routinely measure macroscopic composite mechanical properties such as tensile strength, and determine residual fibre length (the techniques for which have been developed by many to semi or fully automated processes). A series of papers by Bader and Bowyer $(21,22)$ in the early seventies presented a method for deriving values for $\tau$ (the IFSS) and $\eta_{\mathrm{o}}$ (a fibre orientation factor) from a simple combination of the tensile stress-strain curve and the composite fibre length distribution. It is interesting to note that, despite the recent wealth of activity in the development of micromechanical test techniques (or perhaps because of it ) there has been little follow-up to these papers. In this paper we show how the original analysis can be extended to obtain another important micromechanics parameter, $\sigma_{\mathrm{uf}}$ - the average fibre stress at composite failure. We present an improved version of this macromechanical method and illustrate its application to injection moulded glass-fibrereinforced polypropylene (PP) composites.

\section{EXPERIMENTAL}

Owens Corning Cratec ${ }^{\mathrm{TM}}$ 146B-20C chopped E-glass and Huntsman P4C6Z-059 polypropylene (MFI=35 g/10min) were used to produce moulded composites with $0,10,20$, $30,40 \% \mathrm{w} / \mathrm{w}$ glass contents. The level of fibre-matrix interaction in these composites was changed by the addition (HMPP series) or omission (HPP series) of 2 phr MA-PP coupling agent (Polybond 3200, Uniroyal Chemical Co. Inc.). The glass bundles and pre-dried resin pellets were dry blended to the desired glass content and compounded on a single screw extruder (2.5 inch, 3.75:1, 24:1 L/D screw). The compounds were moulded into test bars on a 200-ton Cincinnati Milacron moulding machine. Set point temperatures were $254-282^{\circ} \mathrm{C}\left(490-520^{\circ} \mathrm{F}\right)$ for compounding and $216-238^{\circ} \mathrm{C}\left(420-460^{\circ} \mathrm{F}\right)$ for moulding, at a mould temperature of $66^{\circ} \mathrm{C}$ $\left(150^{\circ} \mathrm{F}\right)$. All mechanical property testing was performed at $23^{\circ} \mathrm{C}$ and at a relative humidity of $50 \%$. Tensile properties were measured in accordance with the procedures in ASTM D-638, using five ASTM Type I specimens at a crosshead rate of $5 \mathrm{~mm} / \mathrm{min}(0.2$ inches/min $)$ and an extensometer gauge length of $50 \mathrm{~mm}$ ( 2 inches). Flexural properties were measured on five specimens in accordance with the procedures in ASTM D-790, at a crosshead rate of 2.5 $\mathrm{mm} / \mathrm{min}(0.1$ inches/min) and a span width of $50 \mathrm{~mm}$ ( 2 inches). Fibre length and diameter distributions were determined by image analysis and optical microscopy on fibre samples removed from the moulded bars after high temperature ashing. Measurement of fibre orientation was carried out on cross sections of moulded tensile bars that were cut perpendicular to the melt injection direction. The sections were polished and a series of optical micrographs was taken systematically across the thickness of the bar. The orientation of any fibre can be determined from its elliptical profile using the equation $(1,23)$

$\cos (\phi)=\mathrm{W} / \mathrm{L}=4 \mathrm{~A} / \pi \mathrm{L}^{2}$

where $\phi$ is the angle the fibre axis makes with the flow direction, $\mathrm{W}$ is the minor axis of the ellipse which should also represent the fibre diameter, $\mathrm{L}$ is the ellipse major axis, and $\mathrm{A}$ is the area of the ellipse. Either of possibilities in equation 1 may be used, however it has been shown (24) that the greatest experimental error comes from the measurement of $\mathrm{W}$ and that the area method produces values with a lower degree of uncertainty. The Hermans orientation parameter $\left(\mathrm{f}_{\mathrm{p}}\right)$ can be calculated from this data using 
$\mathrm{f}_{\mathrm{p}}=2<\cos ^{2}(\phi)>-1$

where the average value of $<\cos ^{2} \phi>$ is approximated by

$<\cos ^{2}(\phi)>=\sum_{\mathrm{i}}\left[\mathrm{N}\left(\phi_{\mathrm{i}}\right) \cos ^{2}\left(\phi_{\mathrm{i}}\right)\right] / \sum_{\mathrm{i}}\left[\mathrm{N}\left(\phi_{\mathrm{i}}\right)\right]$

The values of $\mathrm{N}\left(\phi_{\mathrm{i}}\right)$ must first be adjusted (24) by dividing by $\cos \left(\phi_{\mathrm{i}}\right)$ due to the lower probability of the section crossing fibres with higher values of $\phi$. Since the other orientation factors which we will discuss fall in the range 0-1 we will continue this discussion in terms of $<\cos ^{2}(\phi)>$ which for simplicity we will also call an orientation factor and which is directly related to $f_{p}$ through equation 2 .

\section{RESULTS}

\section{Composite Properties}

The results for the tensile moduli as a function of fibre concentration are shown in Figure 1. The data for flexural moduli followed an identical trend. It can be seen that the stiffness of these mouldings increases almost linearly with increasing fibre concentration up to the $40 \% \mathrm{w} / \mathrm{w}$ level. Furthermore, there appears to be little significant effect from the addition of the MA-PP coupling agent on the modulus of these composites. This is inline with the expectation that the elastic properties of the matrix are little changed by any increased fibre-matrix interaction. Despite the fact that most practical mouldings are mixed according to weight fractions, analysis of composite properties is normally carried out considering fibre volume fraction since many underlying structure-performance relationships are linear in volume fraction. Fibre volume fraction $\mathrm{V}_{\mathrm{f}}$ is calculated from fibre weight fraction $\mathrm{W}_{\mathrm{f}}$ using the equation

$V_{f}=\left[1+\frac{\rho_{f}}{\rho_{m}} \frac{1-W_{f}}{W_{f}}\right]^{-1}$

which requires both the fibre $\rho_{\mathrm{f}}$ and matrix density $\rho_{\mathrm{m}}$ as input parameters. It is common practice to use the resin density as the matrix density (for PP $905 \mathrm{~kg} / \mathrm{m}^{3}$ ). However, it should be realised that there is always a strong possibility that the resin has been modified by the presence of the fibres and that the density of the matrix may be different from that of the resin for a number of reasons (e.g. nucleating effect of the fibres, molecular conformation effects of polymer chains at an interface, effects due to dissolution and reaction of the sizing).

Nevertheless, when the tensile modulus is examined as a function of fibre volume fraction we obtain an excellent linear relationship (see Figure 2). The data in Figure 2 can be modelled using a simple rearrangement of the "rule-of-mixtures" equation

$$
E_{c}=\left(\eta_{0} \eta_{l} E_{f}-E_{m}\right) \cdot V_{f}+E_{m}
$$

Using the linear regression parameters shown in Figure 2 results in an average value of $\eta_{\mathrm{o}} \eta_{1} \mathrm{E}_{\mathrm{f}}$ $=43.1 \mathrm{GPa}$. We can use the fibre length data reported later in Figure 6 to calculate the $\eta_{1}$ factor (average $=0.9$ ) using the Cox shear lag method $(25,26)$ which then gives a remaining value of $\eta_{\mathrm{o}} \mathrm{E}_{\mathrm{f}}$ of $47.9 \mathrm{GPa}$, resulting in an $\eta_{\mathrm{o}}$ value of 0.67 when $\mathrm{E}_{\mathrm{f}}=72 \mathrm{GPa}$. This is in the same range 
(0.65-0.72) recently reported for Polyamide 6,6 and PBT based injection moulded composites $(27,28)$.

The results for the tensile strengths as a function of fibre concentration are shown in Figure 3. In both data sets it can be seen that the composite strength increases with increasing fibre concentration up to $40 \%$. However, unlike the data for modulus the strength data follow a nonlinear relationship. Furthermore, the addition of the MA-PP coupling agent leads to a significant improvement in the strength of these composites, as has been well documented by other authors. The same trends can be observed in the flexural strength data shown in Figure 4. It is interesting to note that these polynomials can be used to predict a maximum in strength at a fibre content (approximately $0.25 \mathrm{v} / \mathrm{v}=50 \% \mathrm{w} / \mathrm{w}$ ) for the MA-PP coupled system than for the uncoupled PP (approximately $0.17 \mathrm{v} / \mathrm{v}=35 \% \mathrm{w} / \mathrm{w}$ ). The non-linearity of the strength versus fibre content relationship has also been noted is injection moulded glass reinforced PA6,6 and PBT $(27,28)$ Although these results may imply that it might be advantageous to add up to $50 \% \mathrm{w} / \mathrm{w}$ of glass reinforcement to coupled PP, processing difficulties often lead the glass content in these extruded compounds to be limited to a maximum of $40 \% \mathrm{w} / \mathrm{w}$. The results for the tensile elongation as a function of fibre concentration are shown in Figure 5. The addition of even a small fraction of reinforcement dramatically lowers the tensile elongation of the system from a PP resin value of $9.6 \%$. At higher fibre loadings the elongation values continue to decrease slightly with increasing fibre concentration. However, the addition of the MA-PP coupling agent does mitigate the negative effect of fibre reinforcement on the tensile elongation to some degree.

\section{Fibre Length}

It is well known that the processing of glass fibres into injection moulded composites leads to large reductions in the fibre length (8-17). Figure 6 shows the weight average residual fibre length $\left(\mathrm{L}_{\mathrm{w}}\right)$ versus fibre concentration. It can be seen that the $4 \mathrm{~mm}$ chopped fibres used in this study were reduced to 1-2 mm length by the compounding and moulding process. This is a much less severe length reduction that reported for PA6,6 and PBT based injection moulded composites. Those data were reported for 14 micron diameter fibres. It has been shown that residual fibre length appears to be inversely proportional to fibre diameter in injection moulded composites (REF CST PA66) and since the fibre used in this study were approximately 20 micron diameter that may explain the lower level of fibre length degradation in this case. However, the glass content also plays a role in determining the residual composite fibre length. Figure 7 shows that the average residual fibre length decreases almost linearly with increasing fibre concentration. This could be due to the fact that increased fibre loadings lead to increased probability of fibre-fibre interaction (and resultant damage) and an increased apparent melt viscosity resulting in higher bending forces on the fibres during compounding and moulding. This decrease in residual fibre length with increasing fibre concentration may well be an important factor in the explanation of why the strength based properties of these composites show a decreasing reinforcement effect as the fibre concentration is increased. It is interesting to note that increasing the level of fibrematrix (or fibre-melt during processing) interaction results in a greater level of fibre length degradation. It could be speculated that this could be explained using the above arguments if we assume that increasing the fibre-melt interaction level leads to an increased effect on the apparent melt viscosity. Despite the increased level of fibre length degradation the overall mechanical performance of the moulded composites is improved by the addition of the MAPP coupling agent. 


\section{Fibre Orientation}

Injection moulded composites exhibit a complex distribution of fibre orientations due to the interactions between melt properties and moulding conditions. As the melt fills the mould there is fountain flow which initially orients the fibres and polymer molecular chains perpendicular to the main flow direction. Fountain flow causes the melt to be deposited on the mould wall with the alignment direction parallel to the mould fill direction. Here it solidifies rapidly and this alignment is retained in the solid article. Further behind the melt front, shear flow dominates and produces fairly uniform levels of fibre alignment. In the very centre of the melt the rate of shear is low and the transverse fibre alignment present at the gate is retained. These general features are apparent in studies of fibre orientation distribution found in the $(1,3,6,17,23)$ literature. Figure 7 shows the values of $<\cos ^{2}(\phi)>$ obtained from a series of micrographs taken across the thickness of injection moulded tensile bars containing $30 \% \mathrm{w} / \mathrm{w}$ glass fibres. The trends observed are identical whether MA-PP coupling agent is present in the system or not. The data show a high average level of orientation in the flow direction with a slightly lower level of orientation in the centre of the bars as discussed above. Values obtained for $<\cos ^{2}(\phi)>$ obtained from these cross sections are presented in Table 1. There is little significant difference between the values obtained at different glass fibre loadings.

\section{MACROMECHANICAL ANALYSIS METHOD}

The analysis method based on the Kelly-Tyson model for the prediction of the strength $\left(\sigma_{\mathrm{uc}}\right)$ of a polymer composite reinforced with discrete aligned fibres (29). This model can be simplified to $\sigma_{\mathrm{uc}}=\eta_{\mathrm{o}}(\mathrm{X}+\mathrm{Y})+\mathrm{Z}$, where $\mathrm{Z}$ is the matrix contribution, $\mathrm{X}$ is the sub-critical fibre contribution, and $\mathrm{Y}$ is the super critical contribution, in reference to a critical fibre length defined by $\mathrm{L}_{\mathrm{c}} \sigma_{\mathrm{uf}} \mathrm{D}$ / $2 \tau$ where $\sigma_{\text {uf }}$ is the fibre strength, $\mathrm{D}$ is the average fibre diameter and $\tau$ is the IFSS. The Kelly-Tyson model assumes that all the fibres are aligned in the loading direction and the equation cannot be integrated to give a simple numerical orientation factor to account for the average fibre orientation. The common approach to this problem is to fit the experimental data using a simple numerical orientation factor $\left(\eta_{\mathrm{o}}\right)$. Bowyer and Bader extended the original KellyTyson concept to model the stress-strain curve of the composite prior to failure $(21,22)$. The basis of their argument was that at any strain value $\left(\varepsilon_{\mathrm{c}}\right)$ there exists a critical fibre length $L_{\varepsilon}=\sigma_{\mathrm{f}}$.D / $2 \tau$. Fibres shorter than $\mathrm{L}_{\varepsilon}$ carry an average stress $=\mathrm{L}$. $\tau / \mathrm{D}$ and fibres longer than $\mathrm{L}_{\varepsilon}$ carry an average stress $=\mathrm{E}_{\mathrm{f}} \varepsilon_{\mathrm{c}}\left(1-\left(\mathrm{E}_{\mathrm{f}} \varepsilon_{\mathrm{c}} \mathrm{D} / 4 \mathrm{~L} \tau\right)\right.$. The composite stress at any strain level may then given by

$$
\sigma_{c}=\eta_{0}\left(\sum_{i}\left[\frac{\tau L_{i} V_{i}}{D}\right]+\sum_{j}\left[E_{f} \varepsilon_{c} V_{j}\left(1-\frac{E_{f} \varepsilon_{c} D}{4 \tau L_{j}}\right)\right]\right)+\left(1-V_{f}\right) E_{m} \varepsilon_{c}
$$

Although $\eta_{\mathrm{o}}$ and $\tau$ are not generally known, values for these factors can be obtained if the composite stress $\left(\sigma_{1}\right.$ and $\left.\sigma_{2}\right)$ at two strain values $\left(\varepsilon_{1}\right.$ and $\left.\varepsilon_{2}\right)$ are known. The matrix contribution $\mathrm{Z}$ was calculated from an independent matrix modulus determination and used to calculate the ratio $\mathrm{R}$ of the fibre contributions at the two strains

$$
R=\frac{\sigma_{1}-Z_{1}}{\sigma_{2}-Z_{2}} \quad R^{*}=\frac{X_{1}+Y_{1}}{X_{2}+Y_{2}}
$$


Equation 6 was then used with an assumed value of $\tau$ to calculate the ratio $\mathrm{R}^{*}$, the theoretical value of $R$. At this point the ratios $R$ and $R^{*}$ are independent of $\eta_{0}$. The value of $\tau$ is then adjusted until $R^{*}=R$, and that value of $\tau$ is used in Equation 6 to obtain a value for $\eta_{o}$ (which is assumed to be the same at both strain levels).

As always one should be fully aware of all assumptions that lie behind any model, which in this case are

- stress transfer across the interface increases linearly from the tips of the fibre inwards to some maximum value

- no fibre-matrix debonding occurs

- an orientation correction factor $\eta_{\mathrm{o}}$ may be applied to account for fibres not oriented in the loading direction

- the factor $\eta_{\mathrm{o}}$ is independent of strain and is the same for all fibre lengths

- the composite matrix properties are the same as the resin properties

- the fibre modulus is known (which may also be different from a textbook value or even a measurement on the fibres used to produce the test samples)

- $\tau$ is independent of loading angle

- fibre diameter is monodisperse

- fibre and matrix stress-strain curves are linear

It should be realised that all available 'micromechanical' methods for obtaining values such as orientation factor and interfacial interaction parameters also require a long list of assumptions to be taken into account, and this method is no different in that respect. However, the macromethod presented here has an enormous attraction in that it utilises data which are readily available from the standard composite mechanical testing and requires only an extra determination of fibre length distribution, which is a common characterisation tool of those working with discontinuous fibre composites. At the time of the original work the method was somewhat time consuming due to the limited computer power available, however nowadays the above equations can be reduced to a simple spreadsheet operation where $\tau$ and $\eta_{\mathrm{o}}$ can be obtained in moments. We have also extended the analysis method to obtain a value for $\sigma_{\text {uf }}$ the maximum fibre stress at composite failure. This can be obtained by inserting the composite breaking stress and strain into the original Kelly-Tyson equation along with the determined values of $\tau$ and $\eta_{\mathrm{o}}$. Consequently, this method can give a complete characterisation of the micromechanical parameters $\eta_{\mathrm{o}}, \tau, \sigma_{\mathrm{uf}}$ of any system. The relative simplicity and cost effectiveness of this approach makes it ideal as an industrial screening tool for product developers.

As shown in the list of assumptions above, in the original analysis it was assumed that the matrix stress contribution in equation 6 could be calculated from the matrix stiffness and the composite strain. It is well known that the stress-strain curve of many thermoplastics is non-linear, even at low strains, Figure 8 shows a typical stress-strain curve for PP in the range 0-3\% strain. The accuracy of this analysis can be substantially improved by measuring the actual stress levels at the strains chosen for the analysis. We have found it even more expedient to obtain polynomial curve fitting parameters for the stress-strain curves of our different matrix polymers between 0 $3 \%$ strain (few composites exceed this range). For the matrix used in this study the stress contribution (in $\mathrm{MPa}$ ) can then easily be calculated for any strain level that we wish to use in the analysis using 


$$
\begin{aligned}
& \sigma_{\mathrm{HPP}}=0.66 \varepsilon^{3}-6.11 \varepsilon^{2}+20.86 \varepsilon \\
& \sigma_{\mathrm{HMPP}}=0.18 \varepsilon^{3}-3.55 \varepsilon^{2}+17.13 \varepsilon
\end{aligned}
$$

The strain values used in the analysis were chosen to maximise the use of the stress-strain data available but were kept the same within each of the two series. Consequently we have chosen $0.5 \%$ and $1.0 \%$ strain to obtain composite stress levels for the analysis in the HPP series and $1.0 \%$ and $2 \%$ in the HMPP series. When these data are combined with the full fibre length distributions (used to calculate the data points in Figure 6) and applied in the procedure described above we obtain values for the parameters $\eta_{\mathrm{o}}, \tau, \sigma_{\mathrm{uf}}$. In Figure 9 the IFSS appears to be decreasing with increasing glass content. The trend appears to be approximately the same for both the HPP and the HMPP series. The influence of the MA-PP coupling agent can be seen as giving an increase in the apparent IFSS of approximately 6.5 MPa.

A number of authors have commented on the role of shrinkage stresses contributing to the stress transfer capability at the interface (30-33). Most composite materials are shaped at elevated temperature and then cooled. Since in most cases the coefficients of linear thermal expansion of thermoplastic polymers are much greater than those of reinforcement fibres this cooling process results in compressive radial stress $\sigma_{\mathrm{R}}$ at the interface. Assuming that the coefficient of friction $(\beta)$ at the interface is non-zero these compressive stresses will contribute a frictional component $\tau_{\mathrm{f}}=\beta . \sigma_{\mathrm{R}}$ to the apparent shear strength of the interface. In the case of thermoplastic polymer matrices where there may often be little or no chemical bonding across the interface these frictional stresses can make up a large fraction of the apparent IFSS. An exact calculation of the frictional fraction of the IFSS requires detailed knowledge of the interfacial friction and the temperature dependence of the stiffness and thermal expansion coefficient of the composite constituents and is beyond the scope of this study. However, we have estimated the magnitude and fibre content dependence of $\sigma_{\mathrm{R}}$ in glass reinforced PP using three different models and fixed room temperature values of the required input parameters (31-33).

The results are shown in Figure 10 and it can clearly be seen that the values obtained for the IFSS using the above macro-method analysis follow an similar trend as the various model calculations of the radial compressive stresses at the interface due to fibre-matrix shrinkage mismatch. By an appropriate choice of coefficient of friction it is possible to obtain a good fit of any of the three models with the experimental data. Figure 11 shows an example of the predictions of Piggott's model combined with values of $\beta$ of 0.4 and 0.7 to give an estimate of the frictional component of the interfacial shear stress. It can be seen that we get excellent agreement with the experimental data. At this point we stress again that we do not wish to imply that any strong relevance should be attached to the value of $\beta$ since the theoretical analysis requires a much greater level of detail (i.e. temperature dependence of many parameters) before it can be considered realistic. However the excellent agreement in terms of the observed trends does imply that shrinkage stress and interfacial friction may play an important role in the IFSS of these materials. Furthermore the reduction in IFSS with increasing fibre content is a factor which, in combination with the fibre length reduction, may explain the reduction of reinforcement effectiveness at high fibre loading.

Table 1 gives a comparison of the orientation factors obtained from equation 6 with those obtained by individual analysis of modulus values using equation 5 and $\left\langle\cos ^{2}(\phi)\right\rangle$ values obtained by optical analysis of polished cross sections as described by equation 3 . None of the data sets indicate a strong dependence of fibre orientation factor on the composite fibre content. 
Moreover, within each analysis method, there is no significant effect observed due to the addition of the MA-PP coupling agent on the resultant fibre orientation factors. However, the potential level of experimental error in obtaining an orientation factor from any of these methods is so large that further detailed interpretation of the data in Table 1 is hardly warranted. It is likely that the values of $\left\langle\cos ^{2}(\phi)\right\rangle$ are significantly higher than the values from the macromechanical analysis, however there is no sound theoretical hypothesis that these values should be equivalent. In fact, only the orientation factor $\eta_{\mathrm{o}}=<\cos ^{4}(\phi)>$ from the Cox-Krenchel analysis of composite modulus might be expected to match the macromechanical orientation parameter obtained from the modulus values $(25,26,34)$. These values can also be calculated from the same data used to calculate $\left\langle\cos ^{2}(\phi)>\right.$ and are also shown in Table 1 . This analysis yields orientation factors of the order of the same order of magnitude as those obtained from the macro-method. We note that the $\left\langle\cos ^{4}(\phi)>\right.$ factor also appears to work well in the prediction of the stiffness of compression moulded Glass Mat Thermoplastic (GMT) (26).

Figure 12 shows the values obtained by the macromechanical analysis for the fibre stress at composite failure. It can be seen that these values also reduce with increasing fibre content. It is debatable as to whether the fibre stress at composite failure can be taken as the fibre strength, however one could certainly argue that these two quantities could be related. The absolute level of maximum fibre stress in these composites $(1.0-2.2 \mathrm{GPa})$ is low compared to the pristine tensile strength of E-glass (3.5 GPa). However these values are of the same order of magnitude as those recently reported by Thomason and Kalinka for the tensile strength $(1.5-2.0 \mathrm{GPa})$ at short gauge lengths of E-glass fibres removed from chopped glass bundles similar to the input materials in this study (18). Thomason et al have also recently demonstrated the wide range of fibre strength to be found in fibres used in GMT. Differences in fibre strength were attributed to different levels of processing damage and fibre sizing protection efficiency (19). They reported values for average E-glass fibre strength as low as $1.1 \mathrm{GPa}$ in fibres extracted from commercial GMT's. Strength reducing flaws of many types can be introduced during processing either through damage by fibre-fibre contact or contact with the fibre handling equipment. Since fibre length reduction during processing occurs through breakage of fibres at their weakest (flawed) point, it seems possible that the process by which fibre length is reduced with increasing fibre concentration (Figure 6) could also result in increased levels of strength reducing flaws in the unbroken fibres.

There is also a large effect due to the presence of the MA-PP coupling agent observed in Figure 12. The action of MA-PP coupling agent in improving the stress transfer to the fibres at high strains is well known. However, it is difficult to propose a realistic mechanism by which MA-PP coupling agent would reduce the fibre flaw density in these fibres - consequently leading to higher apparent fibre strength. The stress values in Figure $12 \mathrm{can}$ be converted to fibre strain at failure through the fibre stiffness ( $72 \mathrm{GPa}$ ). Fibre strain at composite failure calculated using the macro-method fibre stress values is compared with the experimental composite tensile strain at failure in Figure 13. The agreement is excellent. This indicates that the failure mechanism in these composites appears to be strain related and not stress related. 


\section{CONCLUSIONS}

We have presented a method for deriving values for the interfacial shear strength, a fibre orientation factor, and the fibre stress at composite failure from a simple combination of the tensile stress-strain curve and the residual fibre length distribution of injection moulded glass-fibre-reinforced thermoplastic composites. The interpretation of the parameters obtained from this macromechanical method is no more or less open to discussion than those parameters obtained by single fibre micromechanical methods. However, this method is much less labour intensive and consequently more cost effective. Furthermore, it has the advantage that the values are obtained from analysis of "real" composites. Data obtained from the macromechanical analysis of injection moulded glass-fibre-reinforced PP indicated that the apparent interfacial shear strength decreases with increasing fibre content, this data was in agreement with the suggestion that residual interfacial radial compressive stresses contribute significantly to the interface shear strength in thermoplastic matrix composites. The effect of adding MA-PP coupling agent to the system was quantified as giving an increase of 6.5 MPa to the apparent interfacial shear strength of the glass-fibre-PP system. The orientation factor obtained from the macromechanical analysis was in agreement with such factors obtained by other methods. The fibre stress at composite failure also showed a fibre concentration dependency, decreasing with increasing fibre concentration. Significant differences in the fibre stress at composite failure were found dependent on the addition of the MA-PP coupling agent to the system. Values obtained by the macro-method were in excellent agreement with the experimental values for the composite elongation at failure. Given the wealth of microstructural information obtained from this macroscopic analysis and the low level of resources employed to obtain the data we believe that this method deserves further investigation as a screening tool in composite system development programmes.

\begin{tabular}{|c|c|c|c|c|c|}
\hline & $\begin{array}{c}\text { Glass } \\
\text { Content } \\
(\%)\end{array}$ & $\begin{array}{c}\eta_{\mathrm{o}} \text { from } \\
\text { Composite } \\
\text { Modulus }\end{array}$ & $\begin{array}{c}<\operatorname{Cos}^{2} \phi> \\
\text { optical }\end{array}$ & $\begin{array}{c}\overline{<\operatorname{Cos}^{4} \phi>} \\
\text { optical }\end{array}$ & $\begin{array}{l}\eta_{\mathrm{o}} \text { from } \\
\text { Macro- } \\
\text { method }\end{array}$ \\
\hline \multirow[t]{4}{*}{ HPP } & 10.1 & 0.689 & 0.698 & 0.522 & 0.563 \\
\hline & 20.6 & 0.701 & 0.723 & 0.555 & 0.622 \\
\hline & 30.1 & 0.681 & 0.717 & 0.489 & 0.609 \\
\hline & 39.8 & 0.647 & 0.738 & 0.571 & 0.656 \\
\hline \multirow[t]{4}{*}{ HMPP } & 10.4 & 0.697 & 0.734 & 0.571 & 0.546 \\
\hline & 20.8 & 0.665 & 0.643 & 0.476 & 0.585 \\
\hline & 27.9 & 0.642 & 0.748 & 0.582 & 0.556 \\
\hline & 40.2 & 0.709 & 0.711 & 0.534 & 0.585 \\
\hline
\end{tabular}

Table 1: Summary of various orientation factors for HPP 


\section{$\underline{\text { References }}$}

1. Toll, S. and Andersson, P. O. Microstructure of long- and short-fibre reinforced injection moulded polyamide. Polym.Composites. 1993, 14, 116-125.

2. Takeda, N., Song, D.Y. and Nakatal, K. Effects of temperature and water content on impact properties of injection-moulded glass nylon-6 composites. Adv. Compos. Mater., 1996, 5, 201-212.

3. Moriwaki, T. Mechanical property enhancement of glass fibre reinforced polyamide composite made by direct injection. Composites, 1996, 27A, 379-384.

4. Sato, N., Kurauchi, T., Sato, S. and Kamigaito, O. Mechanism of fracture of short glass fibre-reinforced polyamide thermoplastic. J.Mater. Sci. 1984, 19, 1145-1152 .

5. Horst, J.J. and Spoormaker, J.L. Fatigue fracture mechanisms and fractography of shortglass fibre-reinforced polyamide 6. J. Mater. Sci., 1997, 32, 3641-3651 .

6. Akay, M. and Barkley, D. Fibre orientation and mechanical behaviour in reinforced thermoplastic injection mouldings. J. Mater. Sci., 1991, 26, 2731-2742.

7. Curtis, P.T., Bader, M.G. and Bailey, J.E. The stiffness and strength of a polyamide thermoplastic reinforced with glass and carbon fibres. J. Mater. Sci., 1978, 13, 394-408.

8. Karger-Kocsis, J. and Freidrich, K. Fracture behaviour of injection-moulded short and long glass fibre-polyamide 6.6 composites. Compos.Sci.Technol., 1988, 32, 293-325.

9. Schweizer, R.A. Glass-fiber length degradation in thermoplastic processing. Plast. Compound., 1981, 4(6) 58-62.

10. Shortall, J.B. and Pennington, D. The characterization of fibre length distribution in injection moulded plastics. Plastics Rubber Proc. Appl, 1982, 2, 33-40.

11. Fisa, B. Mechanical degradation of glass fibres during compounding with polypropylene. Polym.Compos., 1985, 6, 232-239.

12. Franzen, B., Klason, C., Kubat, J. and Kitano, T. Fibre degradation during processing of short fibre reinforced thermoplastics. Composites, 1989, 20, 65-76.

13. Bailey, R.S. and Kraft, H. A study of fibre attrition in the processing of long fibre reinforced thermoplastics. Intern. Polymer Processing, 1987, 2, 94-101.

14. Vu-Khanh, T., Denault, J., Habib, P. and Low, A. The effects of injection moulding on the mechanical behaviour of long-fibre reinforced PBT/PET blends. Compos.Sci.Technol., 1991, 40, 423-435.

15. Bailey, R.S., Davies, M. and Moore, D.R. Processing property characteristics for long glass fibre reinforced polyamide. Composites, 1989, 20, 453-460.

16. Thomason, J.L. The influence of fibre properties on the properties of glass-fibrereinforced polyamide 6,6. J. Compos. Mater., 1999, 34, 158-172.

17. Thomason, J.L. The influence of fibre properties of the performance of glass-fibrereinforced polyamide 6,6. Compos. Sci. Technol. 1999, 59, 2315-2328.

18. Thomason, J.L. and Kalinka, G. A technique for the measurement of reinforcement fibre tensile strength at sub-millimetre gauge lengths. accepted by Composites Part A 2000

19. Thomason, J.L., Vlug, M.A., Schipper, G. and Krikor, H.G.L.T. The influence of fibre length and concentration on the properties of glass fibre reinforced polypropylene: 3) Strength and strain at failure. Composites, 1996, 27A, 1075-1084.

20. Various Authors, Special Issue, 6th International Conference on Composite Interfaces. Compos. Sci. Technol.,1997, 57, 825-1185.

21. Bowyer W.H. and Bader M.G. On the reinforcement of thermoplastics by perfectly aligned discontinuous fibres. J. Mater. Sci., 1972, 7, 1315-1321.

22. Bader M.G. and Bowyer W.H. An improved method of production for high strength fibrereinforced thermoplastics. Composites, 1973, 4, 150-156. 
23. Toll, S. and Andersson, P.O. Microstructural characterization of injection moulded composites using image analysis. Composites, 1991, 22, 298-306.

24. Bay, R.S. and Tucker, C.L. Stereological measurement and error estimates for threedimensional fiber orientation. Polym. Eng. Sci., 1992, 32, 240-253.

25. Cox, H.L. The elasticity and strength of paper and other fibrous materials. Brit.J.Appl.Phys., $1952, \mathbf{3}, 72-79$.

26. Thomason, J.L. and Vlug, M.A. The influence of fibre length and concentration on the properties of glass fibre reinforced polypropylene: 1) Tensile and Flexural Modulus. Composites, 1996, 27A, 477-484.

27. Thomason, J.L. Accepted for publication in Compos. Sci. Technol.

28. Thomason, J.L. Accepted for publication in Composites Part A

29. Kelly, A. and Tyson, W.R. Tensile properties of fibre-reinforced metals. J.Mech.Phys.Solids, 1965, 13, 329-350.

30. Di Landro, L. and Pegoraro, M. Evaluation of residual stresses and adhesion in polymer composites. Composites Part A, 1996, 27A, 847-853.

31. Piggott, M.R. in "Load-bearing fibre composites", Pergamon Press, Oxford 1980 pp 203209.

32. Nairn, J.A. Thermoelastic analysis of residual stresses in unidirectional, high-performance composites. Polym. Compos., 1985, 6, 123-130.

33. Thomason, J.L. and Vlug, M.A. The influence of fibre length and concentration on the properties of glass fibre reinforced polypropylene: 4) Impact properties. Composites, 1997, 28A, 277-288.

34. Krenchel, H. in "Fibre Reinforcement", Akademisk Forlag, Copenhagen, (1964)

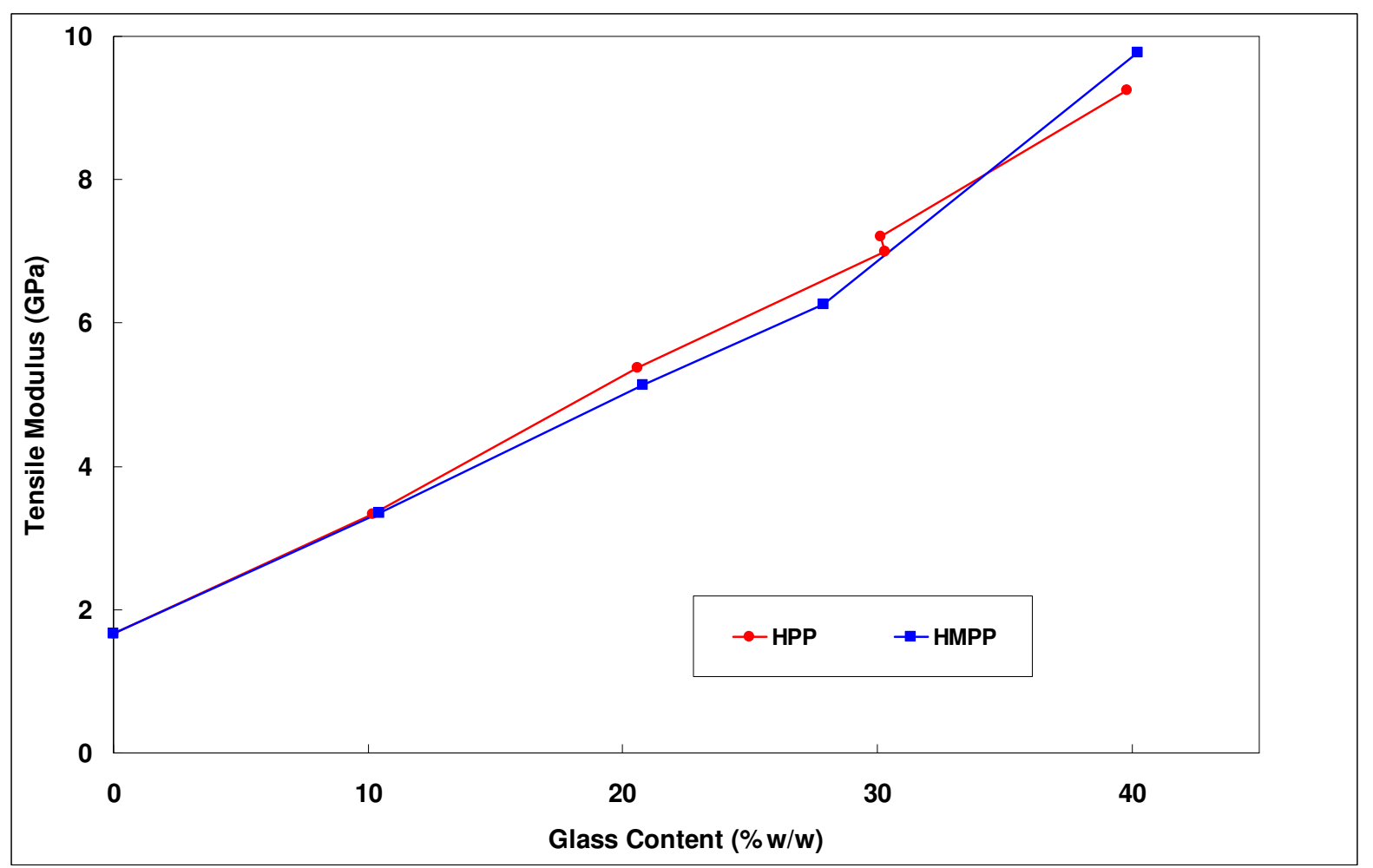

Figure 1 Composite tensile modulus vs fibre weight content 


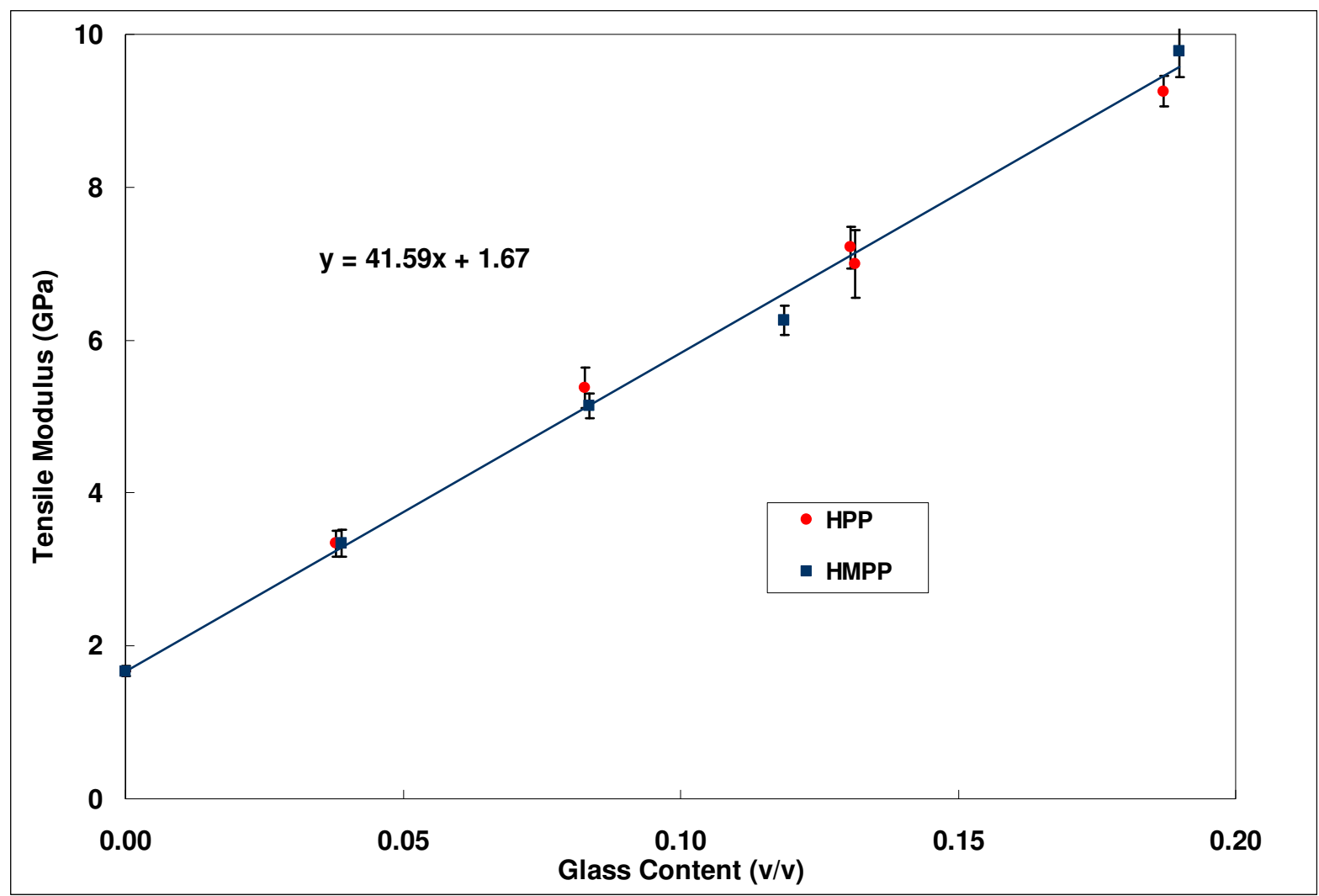

Figure 2 Composite tensile modulus vs fibre volume fraction

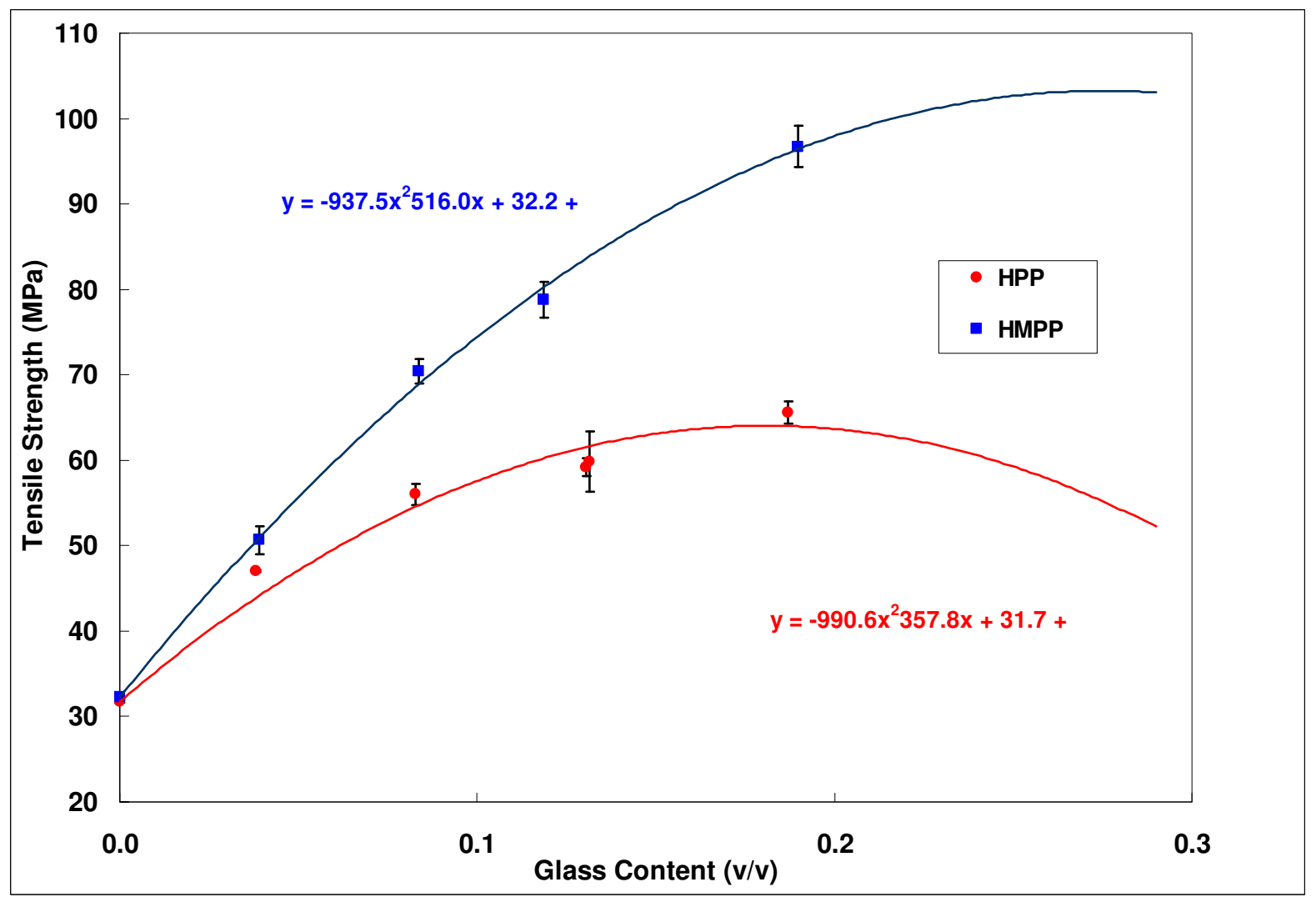

Figure 3 Composite tensile strength vs fibre volume fraction 


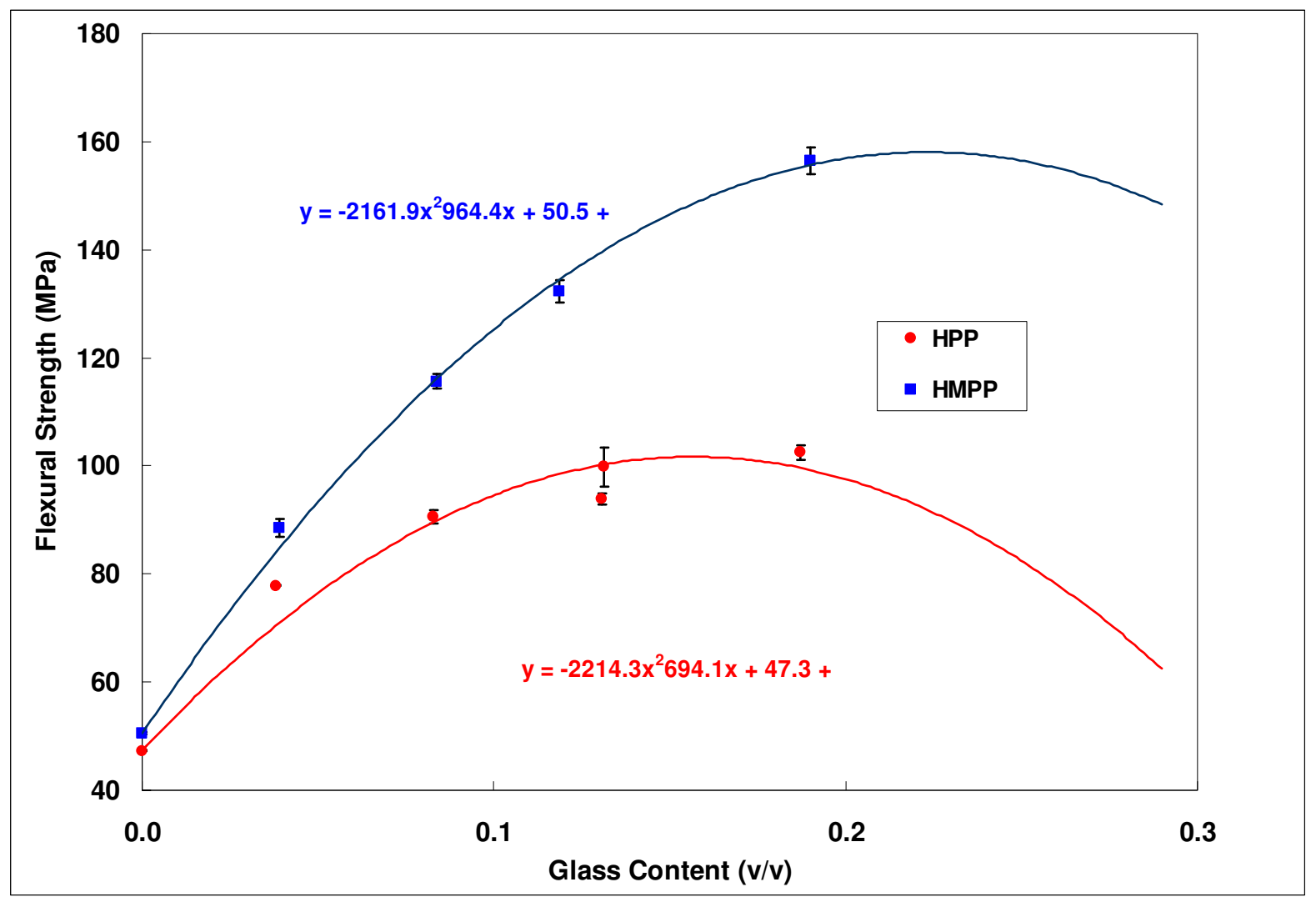

Figure 4 Composite flexural strength vs fibre volume fraction

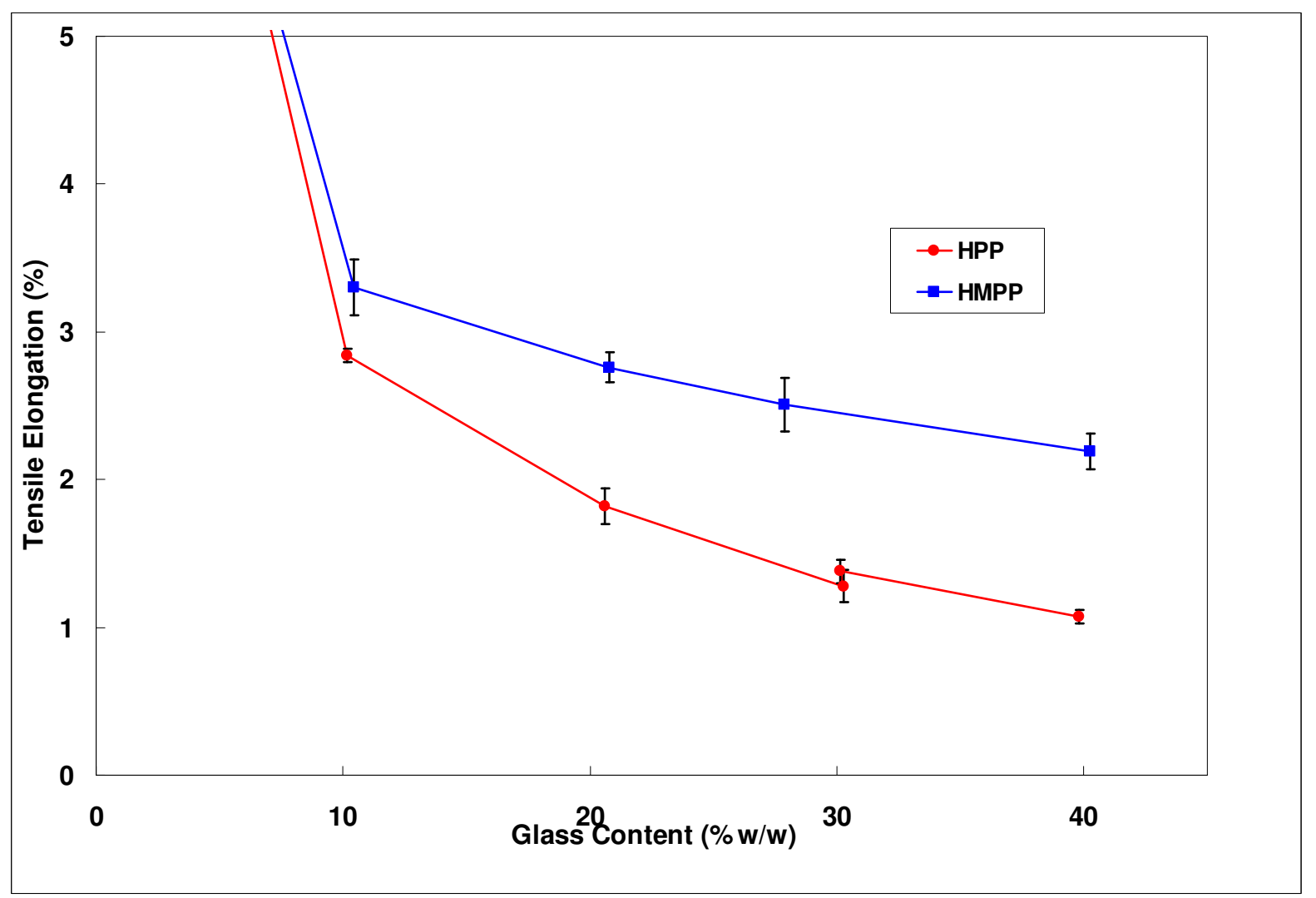

Figure 5 Composite tensile elongation vs fibre weight content 


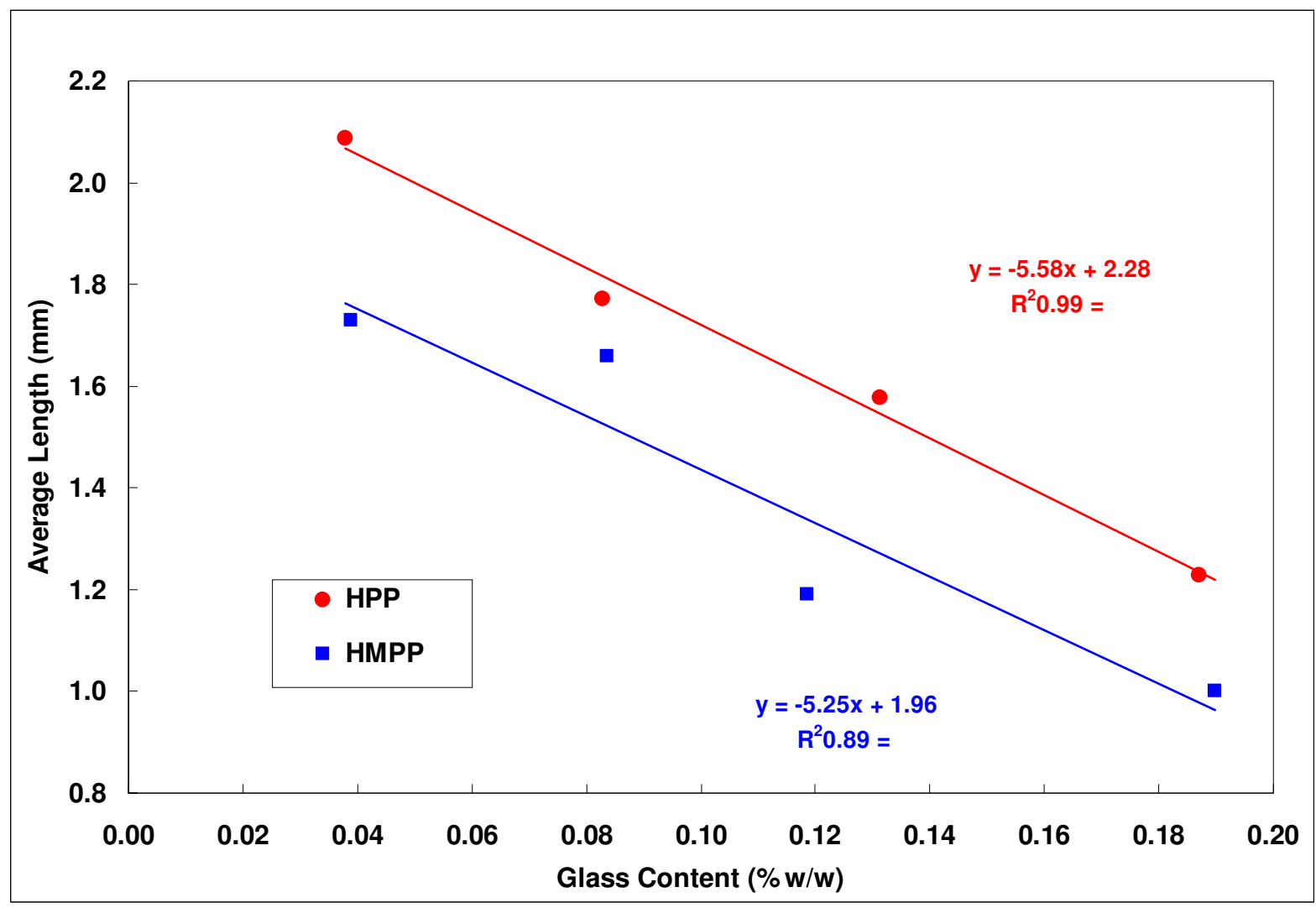

Figure 6 Average residual fibre length vs fibre volume fraction

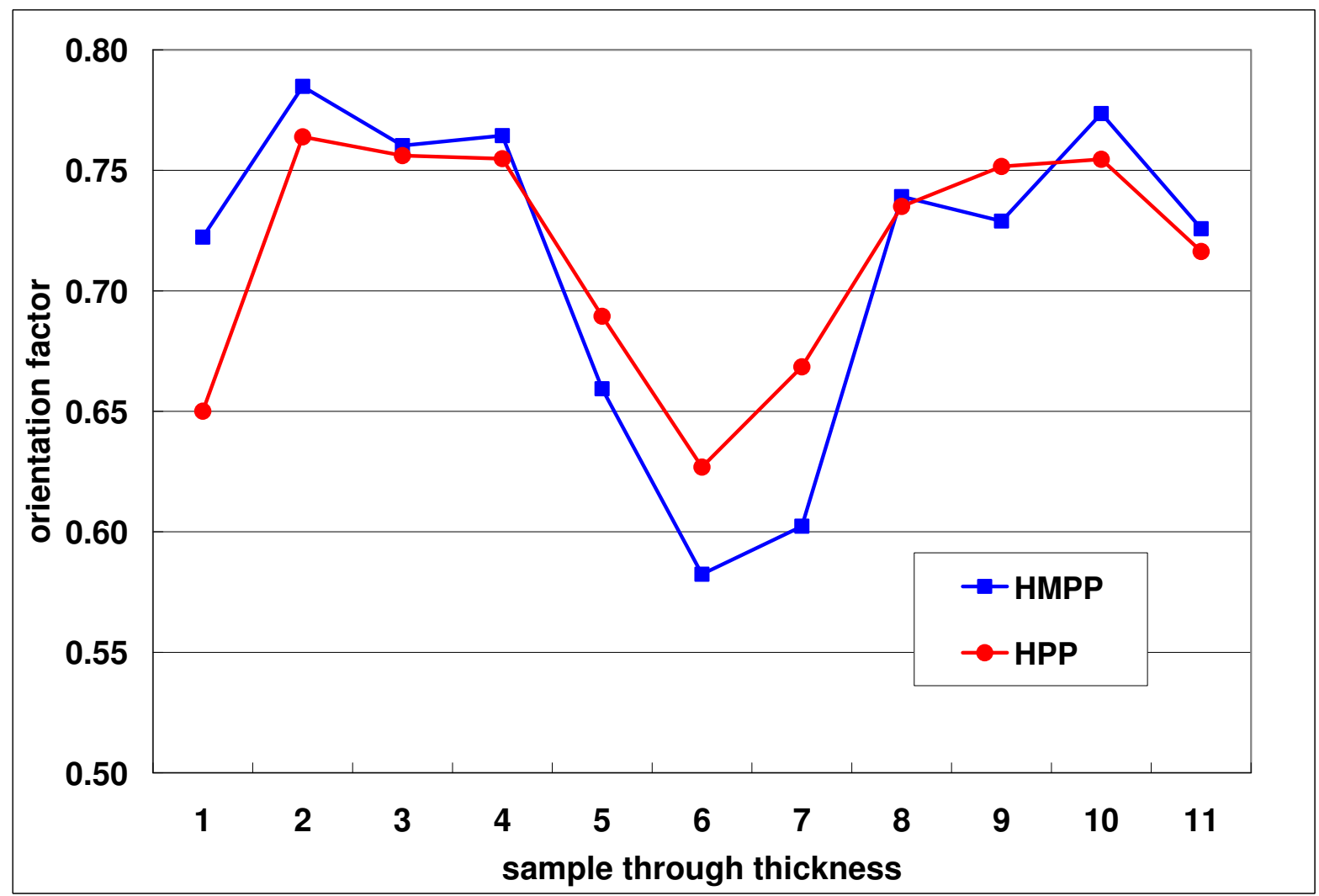

Figure 7 Fibre orientation factor as a function of through thickness position 


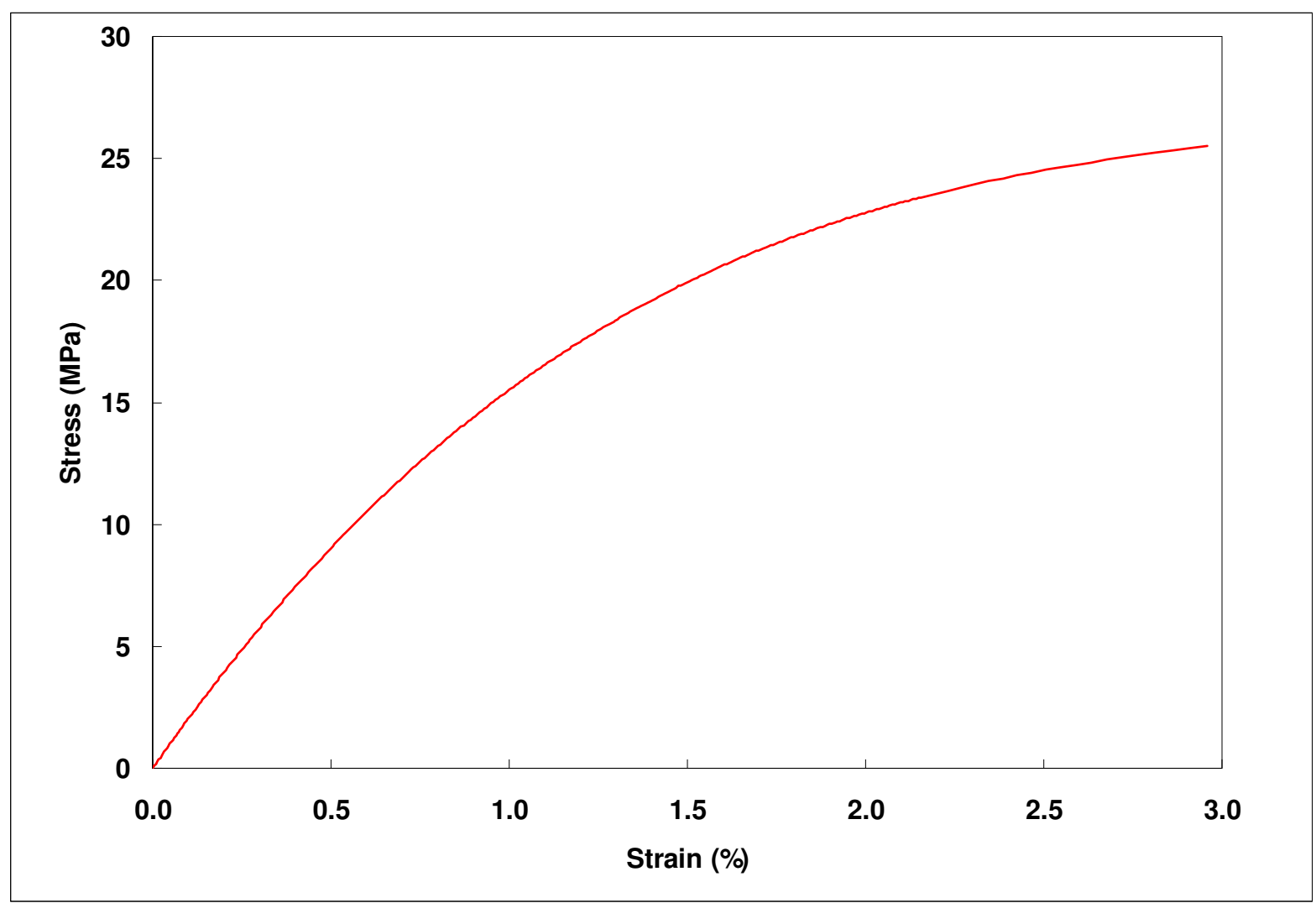

Figure 8 PP stress-strain curve

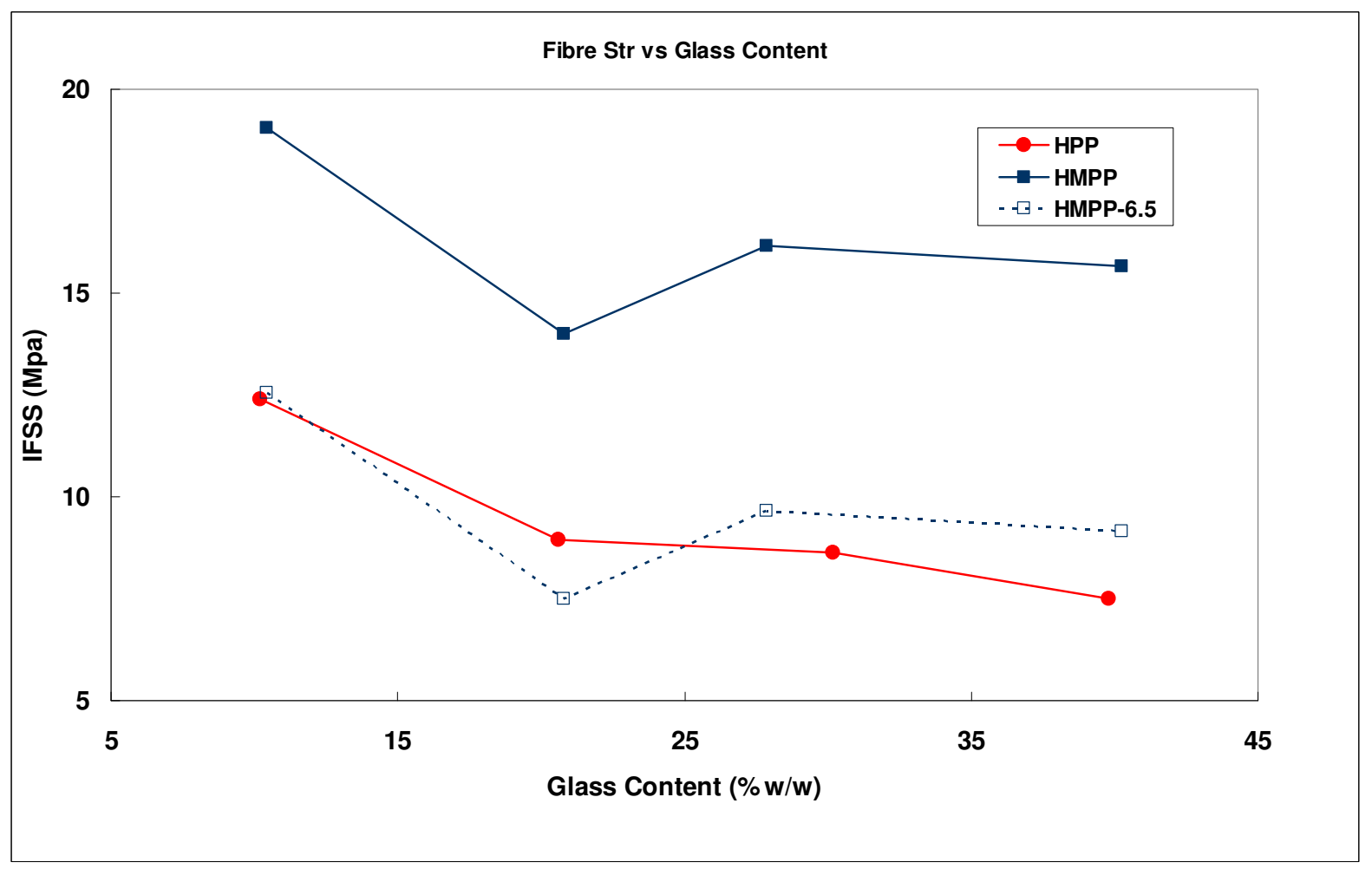

Figure 9 Macro-model results for IFSS 


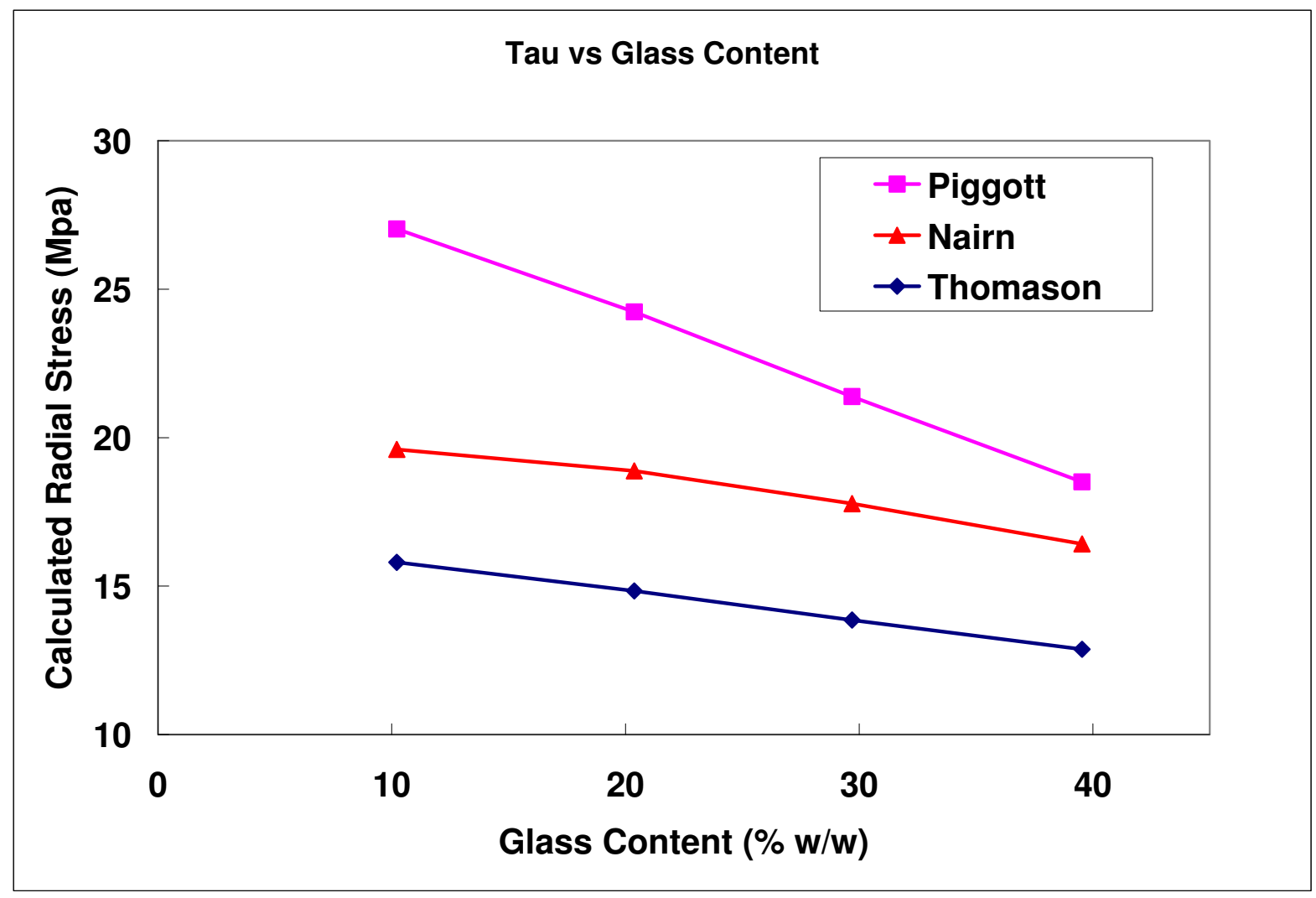

Figure 10 Calculated values of interfacial radial shrinkage stress

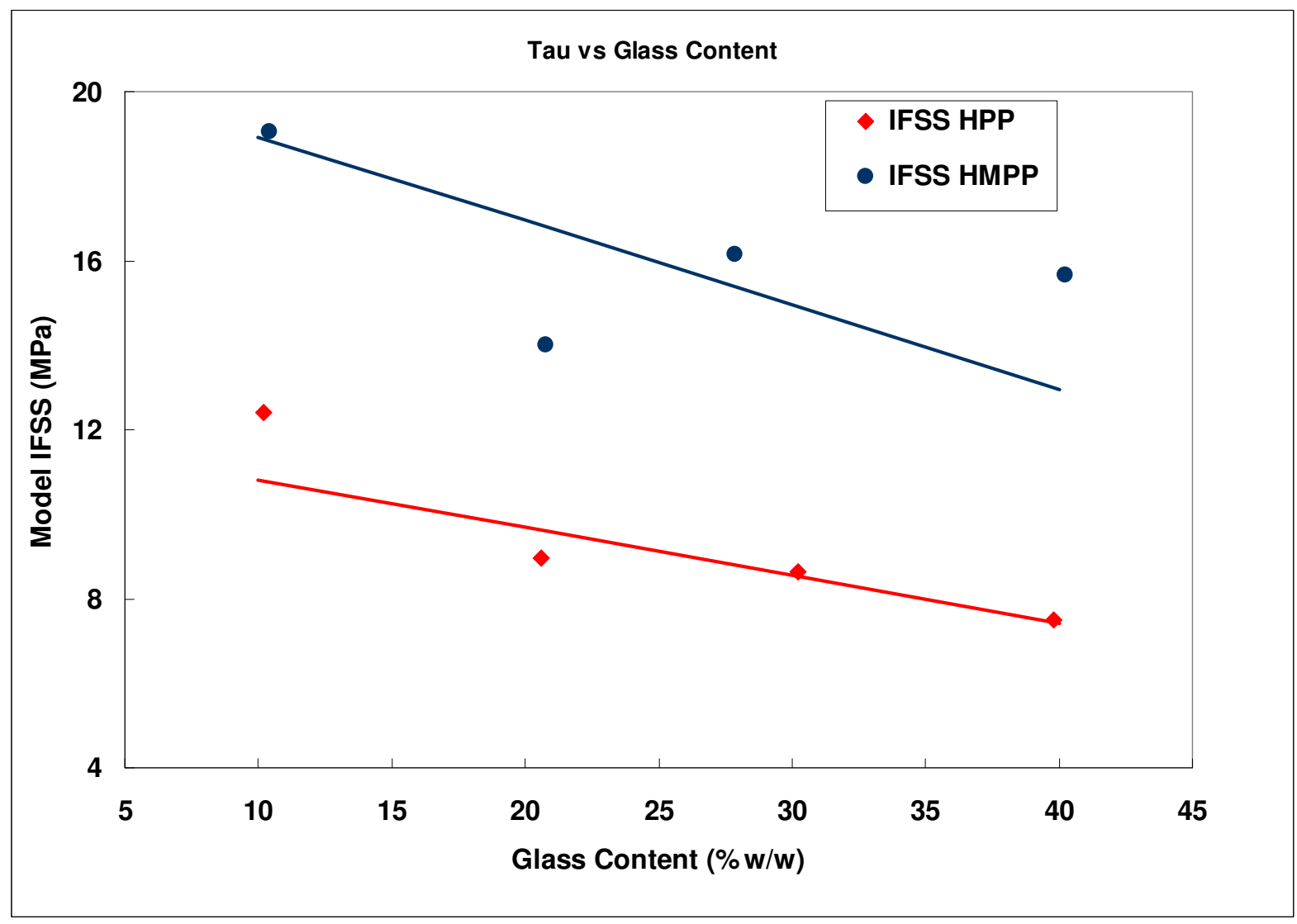

Figure 11 Macro-model results for IFSS and calculated interfacial frictional stress 


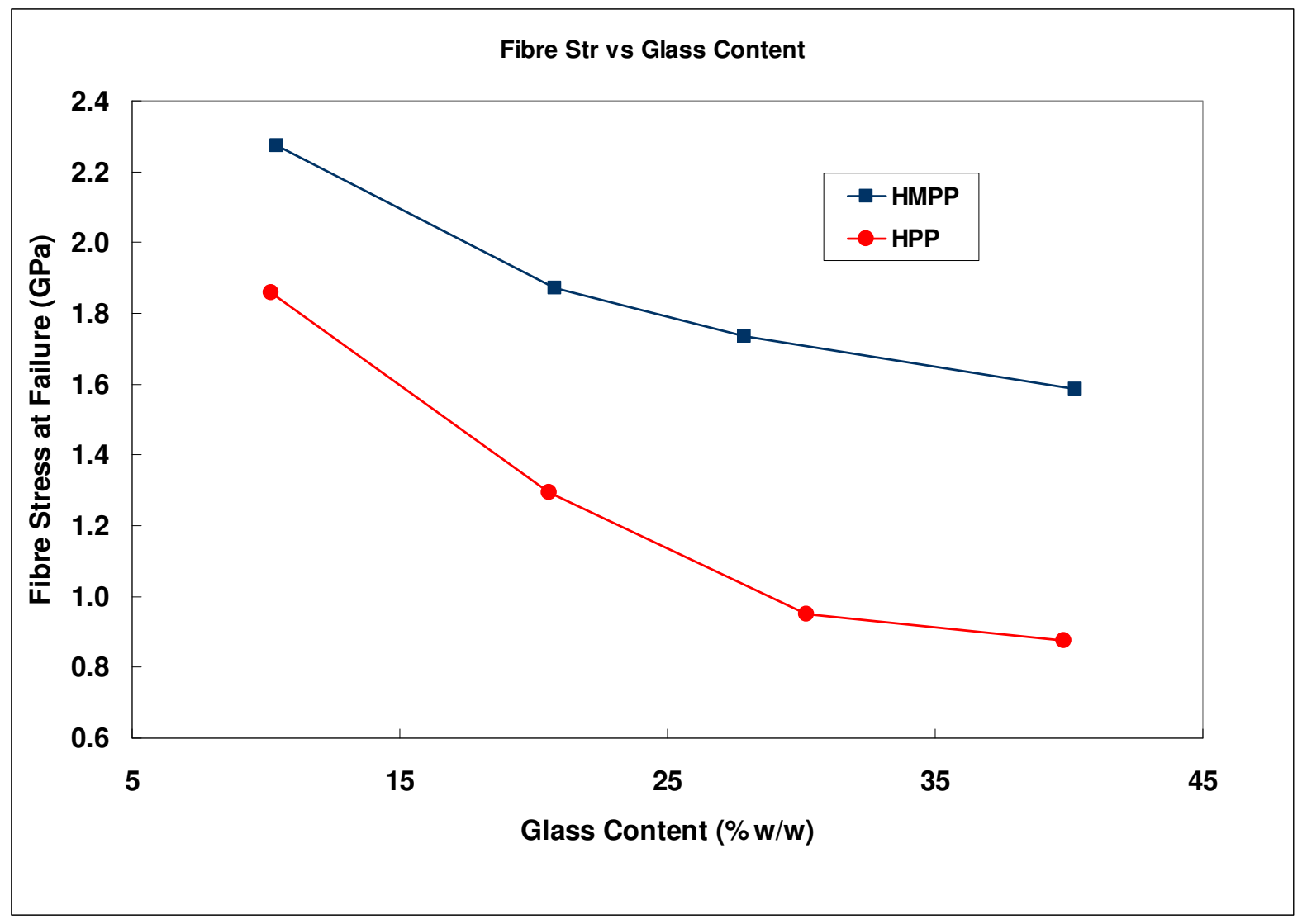

Figure 12 Fibre stress at failure vs fibre weight content

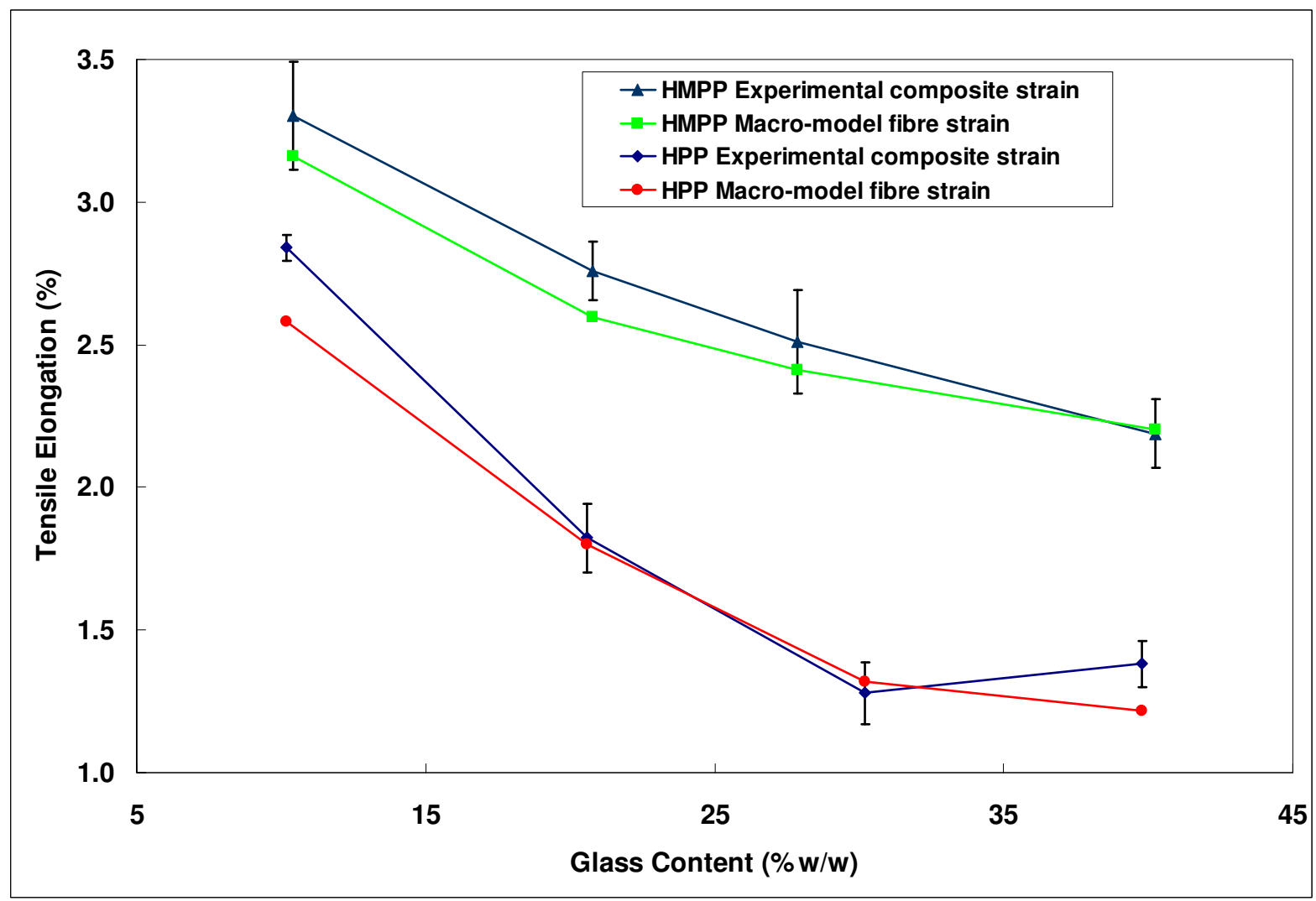

Figure 13 Comparison of macro-model fibre strain and composite failure strain 